\title{
Undergraduate medical education: present state and future needs
}

\author{
Robin C Fraser
}

There is a growing concern that all is not well with undergraduate medical education. Indeed, representatives of 67 countries at the world conference on medical education in 1988 were in little doubt that medical education is in a poor state. ${ }^{1}$ Furthermore, one medical dean has referred to a crisis in undergraduate education, ${ }^{2}$ and some of the shortcomings of medical education have been referred to as scandals. ${ }^{3}$ In 1987 and again in 1988 the General Medical Council (GMC) education committee reported that British medical schools were having difficulty in achieving their educational objectives. ${ }^{45}$ (The claim that medical schools actually had educational objectives came as a considerable surprise to many working within them.) The GMC blamed reductions in funding of the university system and the financial constraints on the NHS. Loss of academic staff between 1981 and 1987 was equivalent to the closure of two medical schools. ${ }^{6}$

I believe that the responsibility for this unhappy state of affairs resides within the medical schools. Although a squeeze on resources has not helped, it has not been the critical factor. I do not believe that improvements in student selection procedures would have a major impact. There is no denying, however, the striking difference between the bright, interesting 18 year olds seen at interview and the weary, disillusioned, unquestioning absorbers of information seen during the clinical years.

The most influential factor in this change must be medical school. Undergraduate teaching is uneven in quality, variable in commitment, and lacking in coordinated objectives. ${ }^{2}$ The main problem is that British medical schools are attracting some of the most able young people in the country and simply boring them to death. The consequence is that the students are the losers. And if medical students are losing out today, patients will lose out tomorrow. ${ }^{2}$

I think that patients are already losing out. Indeed, a large proportion of graduates have a poor grasp of clinical logic, are uncertain in their choice of diagnostic tests, make poor decisions in prescribing, have limited communication skills, and have a poor grasp of ethical principles (D Metcalfe, unpublished work). Even more alarmingly, studies have shown that a significant minority of senior medical students and house officers are deficient in the basic clinical skills of taking a history and making a physical examination. ${ }^{7}$ If matters are to be rectified we need a fundamental rethink of the role of medical schools in producing the doctors of tomorrow. In this paper I examine the current state of undergraduate education.

\section{Perceived importance of teaching}

Unfortunately, some medical schools are less than fully committed to teaching. When one American medical school asked its staff to list the school's needs in descending order of priority, the first mention of anything to do with the education of medical students occupied 16th place. ${ }^{8}$ A major difficulty, therefore, is that students' education is controlled by those whose principal interests lie in areas such as patient care or research rather than in teaching. Medical schools need to be reminded that they are the only institutions with the responsibility of preparing medical students to become doctors; it is a task they must take more seriously.

Even those who are committed to teaching are subverted by the disproportionate importance placed on productivity in research. This is often measured by the number rather than the quality of research publications a department can list. A review of high quality scientific journals has indicated, however, that $55 \%$ of publications are never cited and a further $25 \%$ are cited only once. ${ }^{9}$ Another obstacle to overcome is the shibboleth that to be a good teacher you must first be active and productive in research. ${ }^{8}$ In fact there is much anecdotal support for the opposite view, although it is possible to be good at both research and teaching.

Although a medical school needs to show excellence in both teaching and research, it doesn't necessarily mean that all academic members of staff need to do both. Surely there is room for differential development and attainment - the so called twin track approach. Some could teach more and publish less, and vice versa. The essential difference is that all would be equally valued, and rewarded, providing that appropriate standards were met. If this approach were adopted medical academics would be encouraged to prepare themselves for teaching and those principally occupied in research could concentrate more on quality.

Despite several studies showing the ineffectiveness of clinical teaching little has been done to improve matters. ${ }^{10}$ The medical profession often affirms that teaching is an art and cannot be taught. A medical educationalist, in disagreeing with that view, pointed out that "the root of the problem is not that teaching cannot be taught, but rather that it is not." If medical academic staff are to be involved in teaching they have an obligation to become educators, not just experts in content. This is likely to be a contentious issue as, according to Simon P Capen in 1938, "The question of the preparation of college teachers is highly explosive. Toss it into any academic gathering and the air is instantly filled with the shattered fragments of human dignity, and with cries of triumph and despair." seems that little has changed in the past 50 years.

\section{Some consequences of neglect of teaching}

Sadly, many of those responsible for teaching medical students are unaware of the true purpose of undergraduate education. This was clearly set out by the royal commission on medical education in 1968, which stated that the undergraduate course in medicine should be mainly educational and that its objective was not to produce a fully qualified doctor, but to produce an educated person who becomes qualified in the course of postgraduate training. ${ }^{12}$ Too many medical teachers are still trying to produce "the safe GP." They persist in the impossible task of trying to provide students with a body of knowledge sufficient to sustain them throughout their professional lifetime. This leads to overcrowding of the curriculum, with the emphasis on instruction to the detriment of learning, particularly self learning. There needs to be less formal and timetabled teaching to encourage the development of self learning. Fortunately there are already whispers
Leicester LE2 7LX

Robin C Fraser, FRCGP,

$B M \mathcal{J}$ 1991;303:41-3 
that the long awaited GMC guidelines will recommend a much trimmed core course with options. ${ }^{6}$

Another consequence is that too much attention is paid to instilling and testing recall of factual information. ${ }^{1314}$ As an American professor has observed: "We are in danger of floating off into society the human equivalents of floppy disks" ( $R$ Raekel, personal communication). This is a good analogy because many of our graduates possess voluminous knowledge which they cannot bring to bear unless precisely triggered. Many students have great difficulties in trying to apply their knowledge to a real life problem - for example, every student knows that thiazide diuretics can cause gout, but many will not make the connection when faced with a patient presenting with a painful, inflamed joint and who happens to be taking a thiazide diuretic. This happens because learning too often takes precedence over reasoning ${ }^{15}$ : students memorise the facts but don't try to understand what these facts mean. Thus much of their knowledge remains inaccessible and therefore useless. ${ }^{16}$ Of course, students need to acquire factual knowledge; it should, however, be more selective.

Increased emphasis must surely be placed on the development of cognitive skills and appropriate attitudes. For example, student doctors need to be helped to develop the capacity to think critically, to have scientific and humanitarian values, and to respect the autonomy and dignity of the patient. These attributes are often neglected. ${ }^{3}$

Medical schools can also be accused of imbalance whereby training is favoured over education. Whereas training is directed towards learning to perform specific tasks, education prepares us for the unexpected. ${ }^{17}$ If we train medical students to do merely what is being done now we are condemning them to early obsolescence. They must be equipped to adapt to and cope with the many changes they will inevitably encounter in their professional careers. Future doctors must be able to reason and act in situations which have more than one solution. Teachers must concentrate more on developing powers of judgment. Factual knowledge should be used primarily as a vehicle for developing these skills-skills which can last a professional lifetime.

\section{Hospital versus community based teaching}

Traditionally, the teaching hospital has been the dominant teaching and learning environment for basic medical education. No one would dispute that the teaching hospital has had and still has much to offer student doctors. A hospital is probably the best environment for introducing students to inductive history taking and comprehensive physical examination. Students can be given multiple opportunities, especially in the wards, to memorise the range of questions which patients may need to be asked and to develop skills in eliciting abnormal physical signs (later, hopefully, they will become more selective in both history taking and physical examination). They can also learn how to recognise and manage serious and acute medical conditions, and management will often entail using high technology equipment.

On the other hand, the longstanding imbalance between hospital based and community based teaching and learning has some negative consequences. For example, students have been exposed to highly selected patient populations with the rarest and most serious diseases or at best atypical examples or presentations of the commoner ones. This creates a misleading picture of the real nature and extent of society's medical and health problems.

Hospital based teaching has also tended to concentrate on biological factors. Students are faced with "the notion of the body as a machine, of disease as a consequence of breakdown of the machine, and the doctor's task as repairer of the machine." ${ }^{\prime 18}$ This is a very restricted view because much scientifically credible evidence transcends the biomedical model, casting doubts on the adequacy of the model to explain a wide variety of phenomena associated with health and disease. ${ }^{3}$ Students need to be exposed more to models of care and to teaching which appropriately integrate the physical, social, and psychological aspects of clinical practice.

The traditional drawbacks of hospitals as the predominant bases for undergraduate teaching have been compounded by recent changes in the pattern of health care provision. Increased throughput of patients combined with shorter patient stays and superspecialisation have all adversely affected the ability of hospitals to provide a suitable context for basic medical education. It is therefore becoming increasingly difficult for students to acquire and develop certain skills within the modern teaching hospital. For example, as most patients now reach the wards, and to a lesser extent the outpatient departments, with their condition having already been diagnosed by their general practitioner or through a routine work up, students are denied sufficient practice in diagnostic reasoning. Furthermore, there has been a shift of emphasis towards more primary and community care ${ }^{15}$ Indeed, many observers believe that the modern general practitioner is increasingly occupying the clinical role traditionally occupied by the hospital general physician.

All these factors argue for a much greater emphasis on community based teaching. The steering group on medical and dental education recently wholeheartedly supported the GMC's recommendations on basic medical education in 1980 that medical students should develop an understanding of health and illness in the community and of primary health care. ${ }^{19}$ This points to an enhanced role for general practice.

\section{General practice and undergraduate medical \\ education}

In 1984 the potential contribution of general practice to undergraduate medical education was examined with special reference to the GMC's recommendations of 1980. The subsequent report stated that 16 of the 20 recommendations could not be achieved at any reasonable level by students without using the educational resources of general practice ${ }^{20}$; the report thus highlighted the central relevance of general practice to basic medical education. A later study provided detailed information on the ways in which academic general practice prepares itself for teaching and disclosed the core content and thrust of teaching in general practice. ${ }^{2}$

Undergraduate teaching was seen as the highest priority activity by virtually all academic departments of general practice. Almost all departments produce detailed aims and objectives and provide course books so that both teachers and students have a common understanding of what is required of them. Furthermore, virtually all departments provide some form of training in teaching methods, both for their academic staff and clinical teachers.

Many departments make frequent use of a wide variety of modern teaching methods and techniques, such as video recordings of consultations with both simulated and real patients to teach interviewing, communication, and problem solving skills. Almost all prefer a small group format for departmental teaching, and practice based teaching is usually conducted on a one to one basis. Many courses also include individual and group project work in order to introduce students 


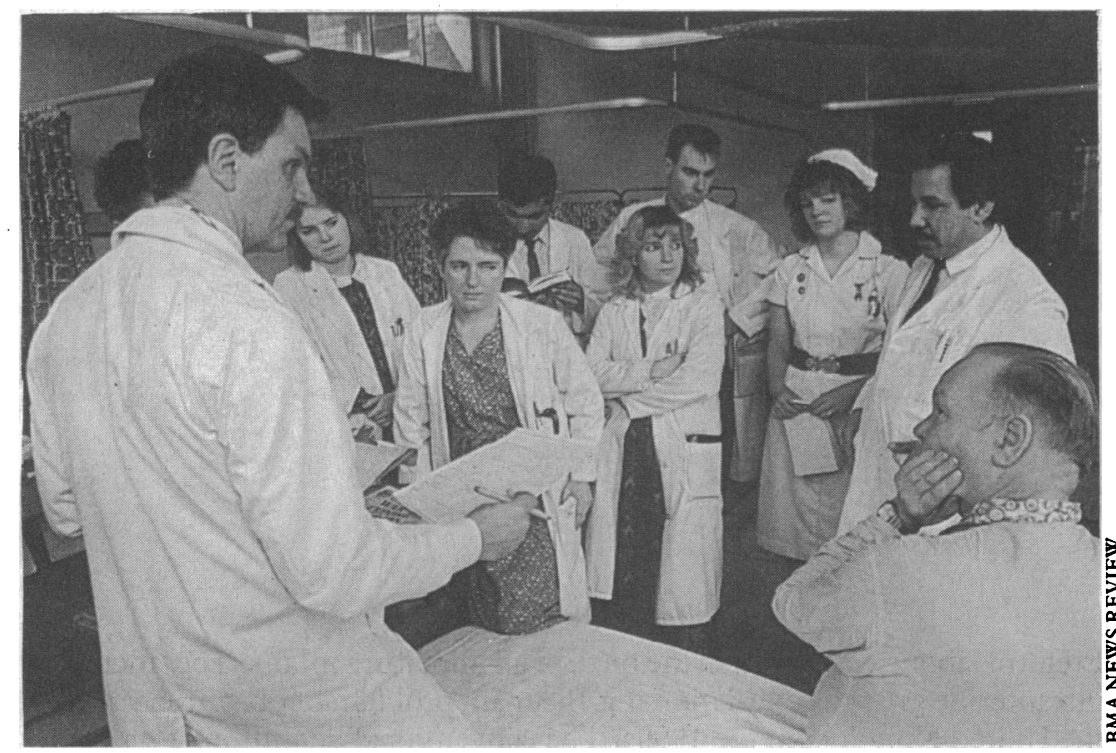

There's not much scope for practising diagnostic reasoning if this patient's condition has already been diagnosed by his GP to self education, reflection, and conceptual and critical thinking - attributes encouraged by the GMC.

In addition to the more traditional content of general practice teaching-namely, community morbidity, long term and continuing care, and the effects of social and psychological factors in illness and disease-most departments seek to develop students' clinical problem solving skills. Indeed, general practice is an ideal setting in which to develop skills, as patients commonly present early with undifferentiated problems and students can make few diagnostic assumptions. Also, most patients' problems are diagnosed and managed entirely within general practice, without recourse to laboratory investigation or hospital referral. This provides students with repeated opportunities to integrate and apply knowledge and skills learnt from the basic, behavioural, and clinical sciences in a discriminating way.

\section{The notion of "entitlement"}

Even if it were possible to eradicate all the shortcomings of the medical curriculum and medical teachers it would still be necessary to overcome the problem of "entitlement," with which a growing minority of medical students is becoming afflicted. "Entitlement" has been described as "a sense of being entitled to attention, caretaking, love, success, income without having to give anything in return."22 Some British students show three of the five salient characteristics of "entitlement." The first is that they believe that it is a student's right to acquire knowledge with minimal exertion-for example, they may demand to be given just the facts or told which pages to read so that they don't read too much. The second is that they think that learning problems are due to inadequacies in anything and anyone other than their own shortcomings-for example, it is their teacher's fault, the fault of the course, etc. The third, and perhaps most distressing, characteristic of "entitlement" is the aggressive response to any feelings of discomfort-for example, if a cherished view is challenged or a limited capacity for critical thinking exposed the student's response too often is to cause a hostile and disrespectful confrontation rather than reflection and participation in a reasoned interchange of views.

The best way of dealing with this phenomenon may be to confront "entitled" behaviour and discuss it openly, rather than sullenly ignore it or respond with an equally "entitled" counter attack. ${ }^{22}$ Otherwise, there is a danger that entitled students will become "entitled" doctors to the detriment of good patient care.

\section{Conclusions}

Undergraduate medical education is in difficulties, although I would not go so far as to say that it is in crisis. Most graduates become competent doctors, but often despite their undergraduate experiences rather than because of them. The need for postgraduate remedial teaching would be greatly reduced if undergraduate curricula were geared to meet the needs of society and to prepare doctors to cope adequately with the rapid changes in medical practice that they will inevitably encounter in their professional lives. Consequently, much more attention needs to be given to the development in students of cognitive skills and self learning techniques. Furthermore, medical schools need to display greater professionalism in their approach to teaching. Finally, many of the current problems of undergraduate education could be solved, or at least substantially reduced, by correcting the current imbalance between hospital based and community based teaching and learning. Student doctors and their future patients would greatly benefit from the students being exposed to the most appropriate elements of the modern teaching hospital complemented by the full involvement of academic general practice.

1 McManus IC, Wakeford RE. A core medical curriculum. BMf 1989;298: 1051

2 Richards P. Departmental divisions and the crisis in undergraduate medical education. $B M$ J 1988;296:1278.

3 White KL. The task of medicine. Menlo Park, California: Henry J Kaiser Family Foundation, 1988.

4 General Medica Council Education Committee. Report of a working party on the teaching of behavioural science, community medicine and general practice in basic teaching of behavioural science, community medicine and general

5 General Medical Council Education Committee. Report of a survey of medical education practices in United Kingdom medical schools. London: General Medical Council, 1988.

6 Harries BJ, Richards JDM, Richards P. Academic medical staff changes in England and Wales 1984-7. Lancet 1987;ii:746.

7 Edelstein DR, Ruder HJ. Assessment of clinical skills using videotapes of the complete medical interview and physical examination. Medical Teacher 1990;12:155-62.

8 Abrahamson S. The state of American medical education. Teaching and Leaming in Medicine 1990;2:120-5.

9 Hamilton DP. Publishing by-and for?-the numbers. Science 1990;250: 1331-2.

10 Daggett CJ, Cassie JM, Collins GF. Research on clinical teaching. Review of Educational Research 1979;49:151-69.

11 Brown G. Microteaching: a programme of teaching skills. London: Methuen and Cole, 1975.

12 Report of the Royal Commission on Medical Education. London: HMSO, 1968. 13 Pickering G. The quest for excellence in medical education. Oxford: Oxford University Press, 1978.

14 Kessell N. Conference of medical academic representatives. $B M \mathcal{J}$ 1984;288:1929.

15 Kaufman A, Kleeper D, Obenshain SS. Undergraduate medical education for primary care: a case study in New Mexico. South Med f 1982;75: 1110.

16 Gale J, Marsden P. Medical diagnosis: from student to clinician. Oxford: Oxford University Press, 1983.

17 Marinker $M$. Changing patterns in general practice education. In: Teeling Smith G, ed. Health education and general practice. London: Office of Health Economics, 1985

18 Engel GL. The need for a new medical model: a challenge for biomedicine. Science 1977;196: 129-36.

19 First Report of the Steering Group on Medical and Dental Education. London: HMSO, 1989.

20 Association of University Teachers of General Practice. Undergraduate medical education in general practice. London: Royal College of General Practitioners, 1984. (Occasional paper 28.)

21 Fraser RC, Preston-Whyte ME. The contribution of academic general practice to undergraduate medical education. London: Royal College of General Practitioners, 1988. (Occasional paper 42 .)

22 Dubovsky SL. Coping with entitlement in medical education. $N$ Engl $\mathcal{F}$ Med 1986;315:1672-4.

(Accepted 24 April.1991) 